Gut, 1961, 2, 346

\title{
Light - and electron-microscope studies of the effects of 4-aminopteroylglutamic acid (aminopterin) on the mucous membrane of the small intestine of the rat
}

\author{
A. WYNN WILLIAMS \\ From the Department of Pathology, University of Edinburgh
}

SYNOPSIS Aminopterin, a cytotoxic agent, causes mitotic arrest by interfering with the catabolism of ribonucleoprotein. The effects on the small intestine are demonstrated. The resulting atrophy, with changes in the microvilli, is associated with severely impaired fat absorption.

The essential cause of the abnormal light microscopic appearances of human jejunal mucous membrane in malabsorption disease is unknown and it has not been decided whether the epithelial changes are the primary cause of malabsorption and nutritional deficiency or whether they are secondary phenomena. So far, experimental attempts to produce strictly comparable chronic intestinal abnormalities in animals have failed. However, gross atrophy of jejunal mucosa was observed in mice (Dustin, 1949; Jacobson, 1951) and in rats (Woll and Oleson, 1951; Vitale, Zamcheck, DiGiorgio, and Hegsted, 1954) given 4-aminopteroylglutamic acid (aminopterin), and the changes deserve special attention not only because human malabsorption may conceivably be dependent on a similar derangement of metabolism but also because cytotoxic drugs are being increasingly used in the treatment of cancer. In this paper a brief account confirming the main findings of these investigators is augmented by a description of electron-microscopic appearances. It is suggested that the latter may be usefully compared or contrasted with ultramicroscopic findings in jejunal biopsies from cases of human malabsorption.

\section{MATERIALS AND METHODS}

Sixty adult Wistar rats, kept on a normal diet and allowed as much water as they wished, were injected subcutaneously each day with aminopterin dissolved in saline. The dose was $300 \mu \mathrm{g}$. per $\mathrm{kg}$. body weight and groups of six animals were killed daily by a blow on the head. The abdomen was opened and portions of stomach, jejunum, ileum, and large intestine were taken for light and electron microscopy. Blocks for light microscopy were fixed in $10 \%$ formol-saline and paraffin sections were stained by haematoxylin and eosin. Tissue for electron microscopy was cut into blocks of approximately $1 \mathrm{c} . \mathrm{mm}$. with a razor blade and placed in Dalton's osmium tetroxide fixative for one hour, dehydrated in graded concentrations of ethanol and embedded in methacrylate (9 parts of butylmethacrylate to 1 part of methylmethacrylate). Sections were cut on a Servall Porter-Blum microtome, using a glass knife. Thicker sections were examined by phase microscopy. Ultrathin sections were examined in a Metropolitan Vickers EM-6 electron microscope. Portions of normal intestine from four control animals, injected with saline only, were also studied. In four of the aminopterin-treated animals killed on the seventh day of the experiment, as well as in two additional control animals, $10 \mathrm{ml}$. corn oil (Mazola) was administered by stomach tube one hour before killing the animals. Frozen sections of jejunum were stained with Sudan III while portions of jejunal mucosa were examined in the electron microscope.

\section{RESULTS}

Four to seven days after starting injections of aminopterin the rats developed diarrhoea. At necropsy the whole of the intestine contained brown watery fluid. There were, however, no inflammatory signs and no haemorrhages. The wall of the small intestine was pale and thinner than normal. Microscopically, there was progressive degeneration and atrophy of the villi, notably in the duodenum and jejunum but also in the ileum. Fig. 1 illustrates the appearance of normal jejunal mucosa in the rat. Five days after the administration of aminopterin, degenerative changes are obvious in the jejunal mucosa (Figs. 2 and 3 ) and the villi 
become stunted and broadened. Some of the epithelial cells show marked hydropic degeneration. Many of the crypts become dilated and lined by thin, atrophic epithelial cells, some showing mitotic arrest. Small numbers of polymorphonuclear leucocytes are seen within the crypts and in the adjacent stroma. The degenerative changes are progressive (Fig. 4) and involve also the ileum (Fig. 5).

No erosions or ulcers were seen at any stage. The stomach appeared normal.

One hour after the administration of corn oil by stomach tube to normal rats the jejunum appears thick and succulent and contains milky fluid in the lumen, and prominent lymphatics are seen in the adjacent mesentery. Moreover, in frozen sections stained with Sudan III fat droplets are numerous within the cytoplasm of the epithelial cells covering the villi. In marked contrast, the jejunum of aminopterin-injected, oil-fed animals is thin, contracted, and pale. The oil remains unabsorbed in the lumen and the mesenteric lymphatics are not seen, while in frozen sections very few cytoplasmic fat droplets are observed and these are confined to a few epithelial cells at the tips of the villi.

In the normal rat, the small intestinal villi are covered by a 'brush border' which is visible in the light microscope as a hazy thickening, or, under the best circumstances, as a striated edge on the epithelial cells. In the electron microscope, the microvilli are seen as a palisade of closely set structures averaging $1.3 \mu$ in length and $0.08 \mu$ in width. Their regular arrangement is a striking feature (Fig. 6). It has been calculated that in human jejunum there are 1,800 microvilli per cell and $1 \times 10^{8}$ microvilli per square millimetre of a mucosal surface. A similar figure was obtained in the rat (Ashworth, Chears, Sanders, and Pearce, 1961). These structures are disposed in a manner which facilitates the formation of pinocytotic vesicles in the subjacent cytoplasm by infolding the cell membrane between the microvilli, when the vesicle is pinched off from the membrane. The cytoplasm within the microvilli and immediately beneath them is devoid of mitochondria but there is a dense, well-defined osmophilic band in this zone, corresponding to the 'terminal web' (Sauer, 1937) seen by light microscopy (Fig. 6). Beneath the terminal web, endoplasmic reticulum and mitochondria are dispersed through the upper apical cytoplasm of the cells.

In rats treated with aminopterin for several days the microvilli are markedly abnormal, being very few and extremely short. The diameter remains normal or is slightly increased. Moreover, the terminal web disappears and the mitochondria appear diminished in size. These features are illustrated in Fig. 7.

One hour after the administration of corn oil by stomach tube to normal rats, droplets of characteristic shape are seen within the cytoplasm of the villous epithelium of the jejunum by electron microscopy (Fig. 8). These are numerous round or oval jet black masses $300 \AA$ to $2 \mu$ in diameter. Similar oil droplets are absent (Fig. 9) or very scanty in the epithelial cells of aminopterin-treated rats except in occasional cells near the tip of the villus where the brush border was seen to be better preserved (Fig. 10).

\section{DISCUSSION}

The cause and significance of the mucosal abnormalities in the small intestine of patients suffering from malabsorption is largely unknown but it is of interest that the most comparable lesions so far produced in the experimental animal are those which follow the administration of antimetabolic substances such as aminopterin. This chemical is an antagonist of folinic acid (leuconostoc citrovorum factor) rather than folic acid and it interferes with the catabolism of ribonucleoprotein (Jacobson, 1951, 1954). The latter investigator demonstrated that aminopterin arrests dividing thick fibroblasts and osteoblasts, also leukaemic cells in metaphase, so that the nuclei are unable to proceed into anaphase. The epithelial cells covering intestinal villi have a life span of a few days. They originate in the crypts of Lieberkühn, where normally there is intense mitotic activity, and they gradually migrate along the surface of the villus until they are shed near or at the tip. Aminopterin produces mitotic arrest in the crypts and, consequently, fewer epithelial cells are available to cover the villus. The cells already present are often larger than normal and cover a larger surface of the villus. A similar sequence of mitotic arrest and epithelial degeneration is seen after abdominal irradiation by $x$ rays (Friedman, 1945). It might be assumed that such cellular expansion would account for the changes in the brush border in aminopterin-treated rats but in fact distension of the bowel of rats does not lead to such gross abnormalities in the brush border (Muir, 1961), and it seems that the cause must reside within the cell. The function of microvilli has not been definitely determined but there is evidence that they are concerned in fat absorption. Palay and Karlin (1956), also Thomas and O'Neal (1960), have suggested that fat may be absorbed in particulate form from the lumen of the intestine. Whether this view is correct or not, the observation reported here that fat is absorbed in aminopterin- 


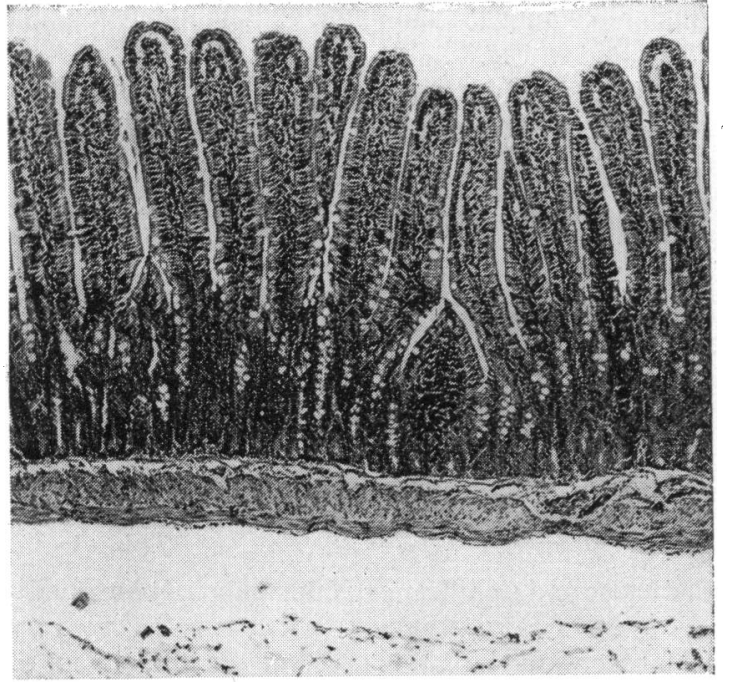

FIG. 1. Normal rat jejunum. Haematoxylin and eosin, $\times 60$.

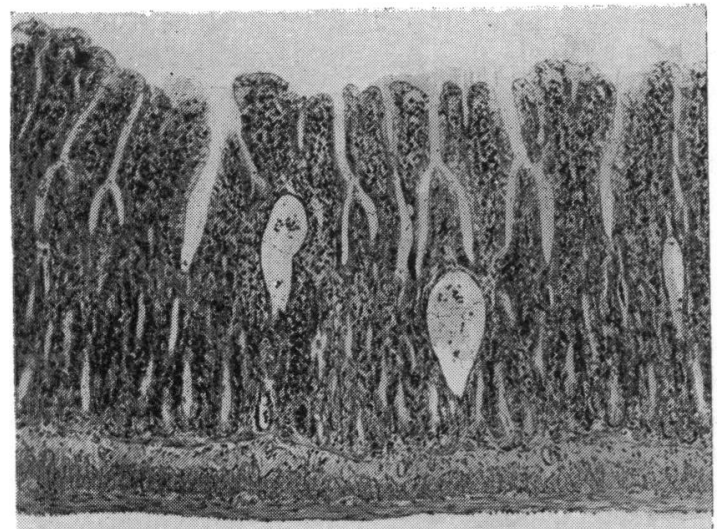

FIG. 2. Jejunum of rat given aminopterin for five days. Haematoxylin and eosin, $\times 60$.

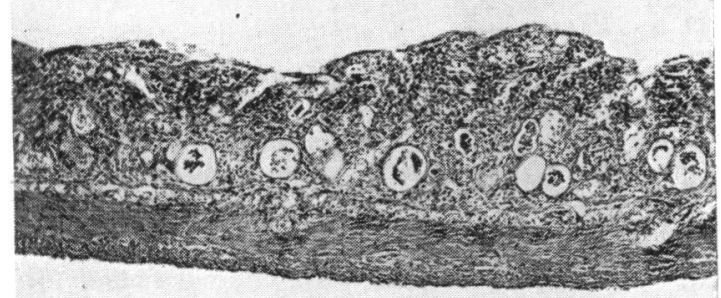

FIG. 5. Degenerate mucosa in ileum of rat given aminopterin for seven days. Haematoxylin and eosin, $\times 60$.

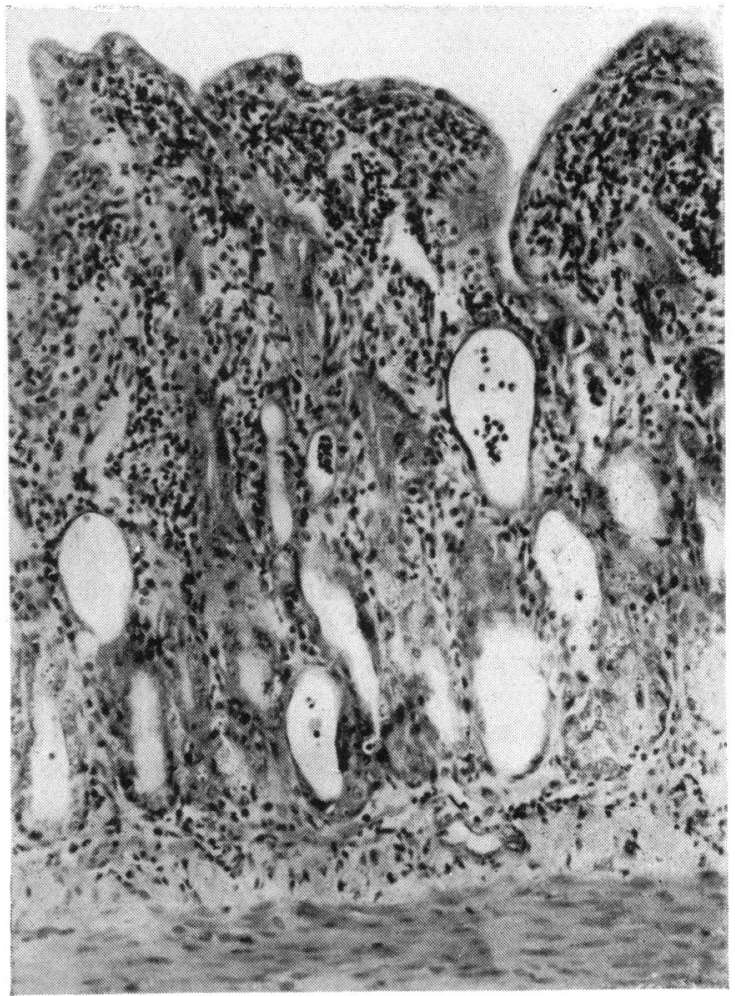

FIG. 3. Jejunum of rat given aminopterin for five days. Haematoxylin and eosin, $\times 130$.

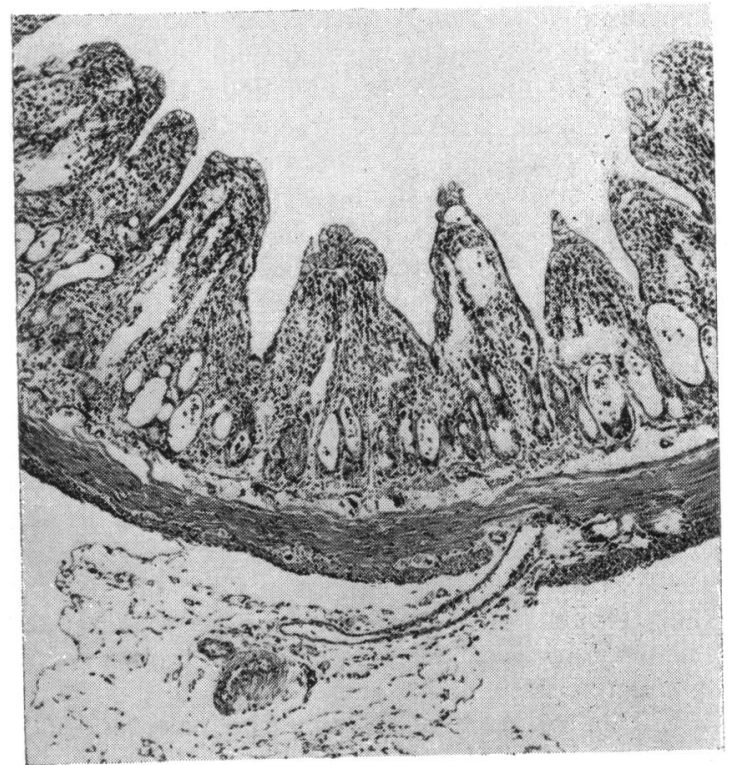

FIG. 4. Advanced degenerative change in jejunum of rat given aminopterin for seven days. Haematoxylin and eosin, $\times 60$. 


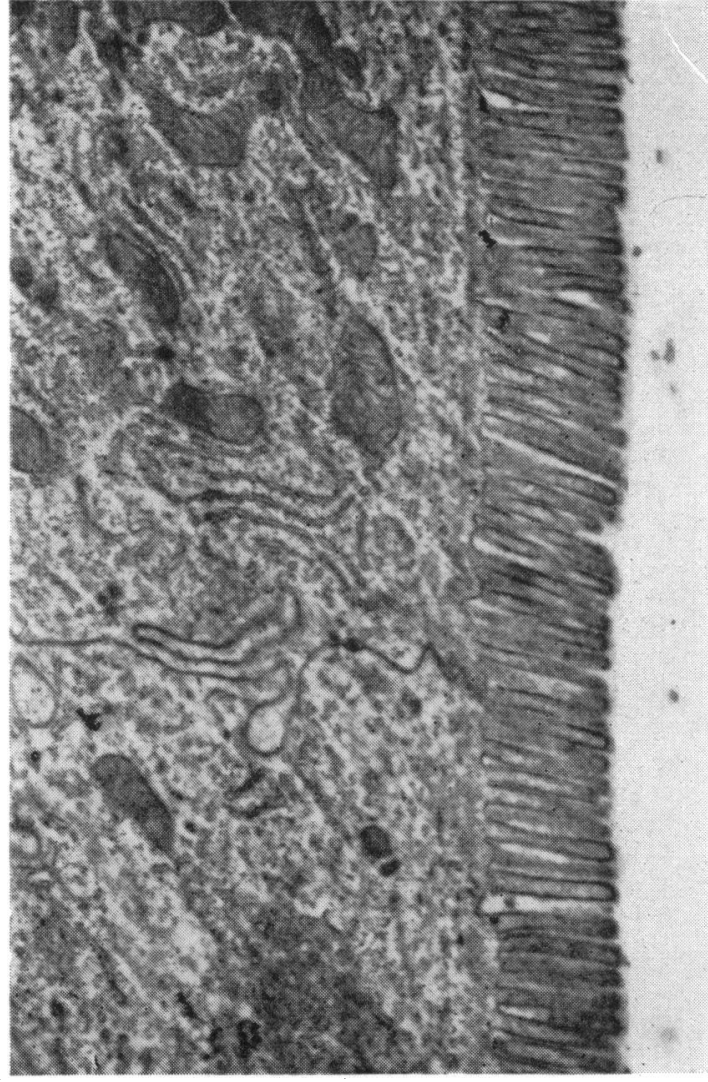

FIG. 6

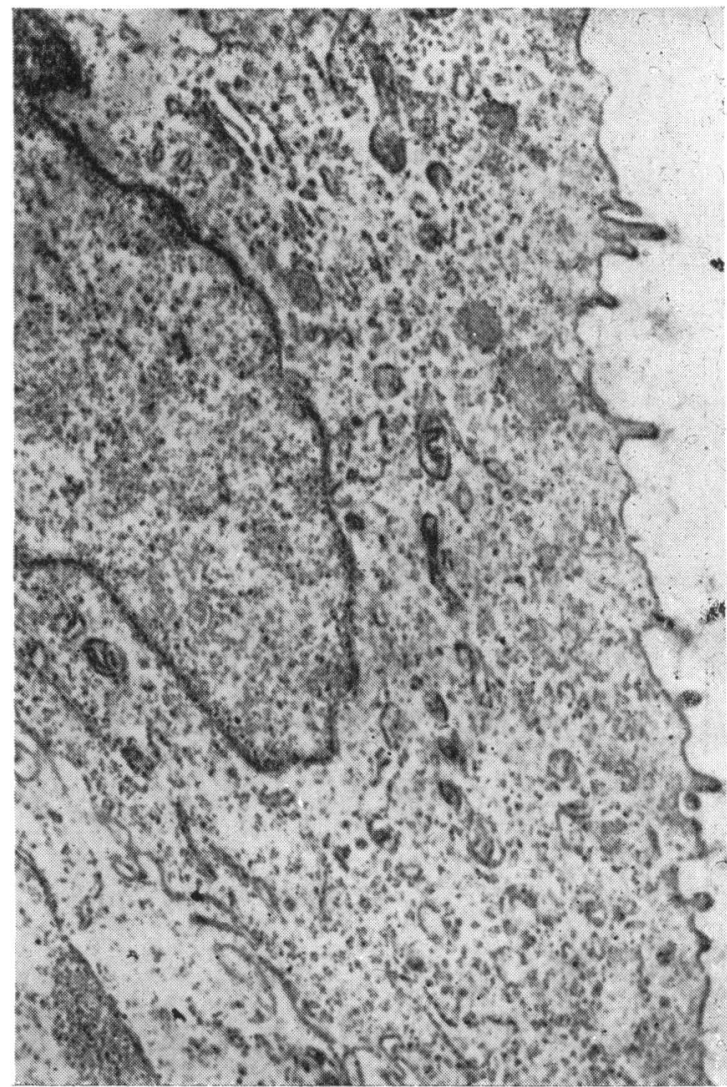

FIG. 7

FIG. 6. Brush border in normal rat jejunum. Portions of two cells are seen, with prominent mitochondria. The terminal web is the dark horizontal line beneath the microvilli. $\times 20,000$.

FIG. 7. Abnormal brush border in jejunum of rat given aminopterin for seven days. $\times 20,000$.

treated rats only in those few intestinal cells in which the brush border was relatively normally preserved supports the concept that the latter is necessary for fat transportation. It is to be expected, therefore, that any reduction in the villous and, more particularly, the microvillous surface of the small bowel must drastically reduce its absorptive capacity. Blunted villi may reduce the surface area to $20 \%$ of normal (Butterworth and Perez-Santiago, 1958), while it has been estimated that the microvilli may account for $95 \%$ of the absorptive area of the small intestine (Hartman, 1959). In primary malabsorption disease in man the villi are often absent or abnormal (Shiner, 1959; Shiner and Doniach, 1960; Fone, Cooke, Meynell, Brewer, Harris, and Cox, 1960) but in some cases light microscopic findings are normal (Girdwood, Dela- more, and Wynn Williams, 1961). The latter investigators studied jejunal biopsies from 24 patients with malabsorptive disease of the idiopathic steatorrhoea type and found no obvious correlation between the type of mucosal appearance and the results of laboratory tests of absorption. Moreover, there was nothing in their results to justify the view that primary malabsorptive disease with absent villi had a different aetiology and symptoms from primary malabsorptive disease with normal villi. Electronmicroscopic studies of human biopsy material may, however, reveal significant abnormalities in the brush border, as has been suggested in one brief report by Ashworth et al. (1961).

I wish to acknowledge the encouragement of Professor G. L. Montgomery and Dr. R. H. Girdwood in this 


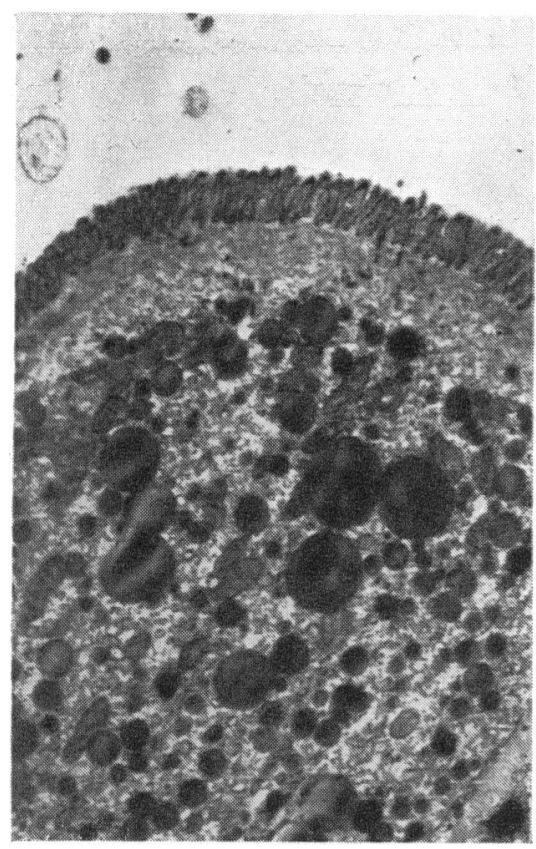

FIG. 8. Part of an epithelial cell covering a jejunal villus in a normal rat, one hour after giving corn oil by mouth. $\times 8,000$.

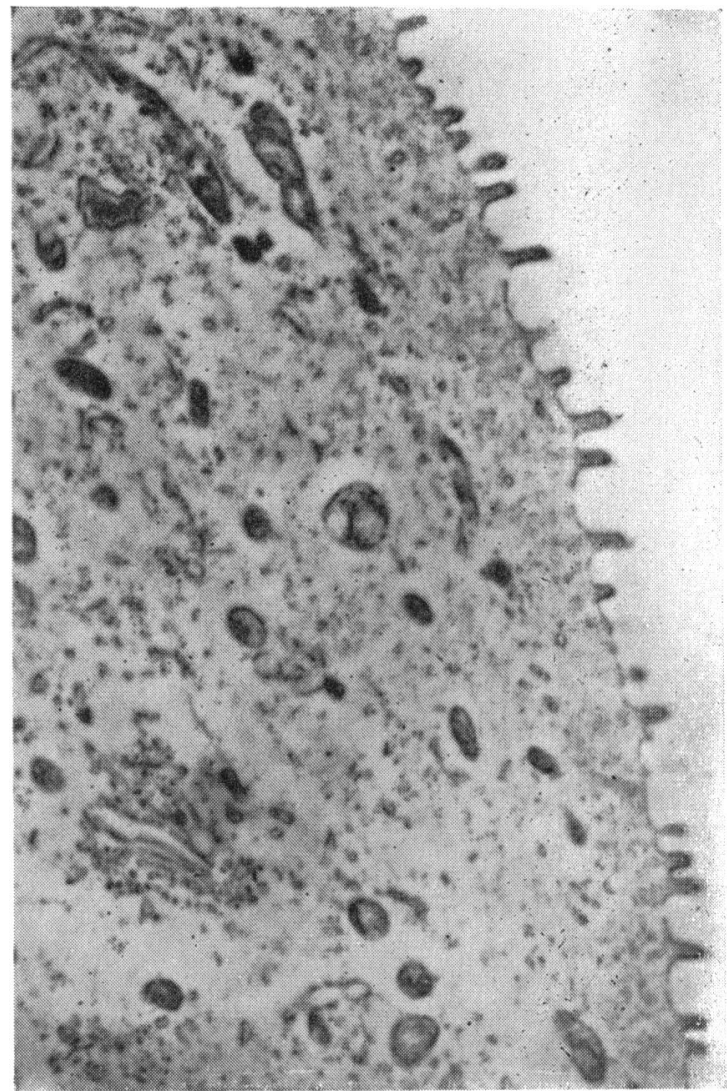

FIG. 9. Part of an epithelial cell covering a jejunal villus in a rat given aminopterin for seven days and corn oil by mouth one hour before death. There are no lipid droplets in the cytoplasm. $\times 20,000$.

FIG. 10. Part of another villous epithelial cell from the same animal as in Fig. 9. Here the brush border is partly preserved and a few lipid droplets are present in the cytoplasin. 
study, also the unfailing technical assistance of Dr. Mary MacDonald, Mr. T. C. Dodds, and Mr. George Wilson. I am also most grateful to the Advisory Committee for Medical Research and the Secretary of State for Scotland for generous financial assistance in this work.

\section{REFERENCES}

Ashworth, C. T., Chears, W. C., Sanders, E., and Pearce, M. B (1961). Nontropical sprue. Fine structure of the intestinal epithelial lesion. Arch. Path. (Chicago), 71, 25.

Butterworth, C. E., Jr., and Perez-Santiago, E. (1958). Jejunal biopsies in sprue. Ann. intern. Med., 48, 8.

Dustin, P., Jr. (1949). Action de deux antagonistes de l'acide folique sur les mitoses intestinales de la souris. C.R. Soc. Biol. (Paris), 143, 1609.

Fone, D. J., Cooke, W. T., Meynell, M. J., Brewer, D. B., Harris, E. L., and Cox, E. V. (1960). Jejunal biopsy in adult coeliac disease and allied disorders. Lancet, 1, 933.

Friedman, N. B. (1945). Cellular dynamics in the intestinal mucosa: The effect of irradiation on epithelial maturation and migration. J. exp. Med., 81, 553.

Girdwood, R. H., Delamore, I. W., and Williams, A. Wynn (1961). Jejunal biopsy in malabsorptive disorders of the adult. Brit. med.J., 1, 319.
Hartman, R. S. (1959). Quoted by Gardner, F. H., and Strauss, E. W., in Advanc. intern. Med., 10, 137 (1960).

Jacobson, W. (1951). The Biology of Cell Division. In Conference on Problems of Ageing: Trans. 13th Conference, 1951, p. 155. Ed. N. W. Shock. Josiah Macy, Jr. Foundation, New York. - (1954). The Mode of Action of Folic Acid Antagonists and the Function of the Leuconostoc Citrovorum Factor. In Ciba Foundation Symposium on Chemistry and Biology of Pteridines, p. 329. Churchill, London.

Muir, A. R. (1961). Personal communication.

Palay, S. L., and Karlin, L. (1956). Absorption of fat by jejunal epithelium in the rat. Anat. Rec., 124, 343.

Sauer, F. C. (1937). Some factors in the morphogenesis of vertebrate embryonic epithelia. J. Morph., 61, 563.

Shiner, M. (1959). Small intestinal biopsy: Diagnostic and research value. Proc. roy. Soc. Med., 52, 10.

Gastroenterology, 38, 419.

Thomas, W. A., and O'Neal, R. M. (1960). Electron microscopy studies of butter and corn oil in jejunal mucosa. A.M.A. Arch. Path., 69, 121.

Vitale, J. J., Zamcheck, N., DiGiorgio, J, and Hegsted, D. M. (1954). Effects of aminopterin administration on the respiration and morphology of the gastrointestinal mucosa of rats. J. Lab. clin. Med., 43, 583.

Woll, E., and Oleson, J. J. (1951). The effects of a folic acid antagonist (aminopterin) on albino rats: A study in the pathogenesis of sprue. Brit. J. exp. Path., 32, 458 . 